BULLETIN Bulletin hispanique

HISPANIQUE Université Michel de Montaigne Bordeaux

123-2 | 2021

Investigaciones semánticas y léxicas actuales

\title{
Katerina Vaiopoulos, Catálogo razonado de las obras de Juan de Matos Fragoso
}

Madrid: Vicos, 2020

Alejandra Ulla Lorenzo

\section{CpenEdition}

Journals

Edición electrónica

URL: https://journals.openedition.org/bulletinhispanique/14542

DOI: 10.4000/bulletinhispanique. 14542

ISBN: 1775-3821

ISSN: 1775-3821

Editor

Presses universitaires de Bordeaux

Edición impresa

Fecha de publicación: 20 diciembre 2021

Paginación: 379-381

ISBN: 979-10-300-0-745-9

ISSN: 0007-4640

Referencia electrónica

Alejandra Ulla Lorenzo, «Katerina Vaiopoulos, Catálogo razonado de las obras de Juan de Matos Fragoso», Bulletin hispanique [En línea], 123-2 | 2021, Publicado el 20 diciembre 2021, consultado el 04 febrero 2022. URL: http://journals.openedition.org/bulletinhispanique/14542 ; DOI: https://doi.org/ 10.4000/bulletinhispanique.14542

Este documento fue generado automáticamente el 4 febrero 2022

Tous droits réservés 


\title{
Katerina Vaiopoulos, Catálogo razonado de las obras de Juan de Matos Fragoso
}

\author{
Madrid: Vicos, 2020
}

Alejandra Ulla Lorenzo

\section{REFERENCIA}

Katerina Vaiopoulos, Catálogo razonado de las obras de Juan de Matos Fragoso, Madrid, Vicos (Biblioteca Filológica Hispana), 2020, 157 pp. ISBN 978-84-9895-242-1.

1 La magnífica obra de la profesora Vaiopoulos que aquí reseñamos supone, sin duda alguna, un trabajo que supera con mucho el concepto de catálogo bibliográfico, puesto que, en la práctica, funciona como una excelente monografía sobre Juan de Matos Fragoso. En este sentido, parece importante recordar que esta investigación se inscribe en el grupo de publicaciones que, en las últimas décadas, ha logrado recuperar la actividad literaria de un grupo de dramaturgos considerados menores por la crítica pero que tuvieron una extraordinaria importancia en la época a través de la composición de piezas de distinto género y finalidad. A este respecto, son varios los autores que se ha ocupado de estudiar aspectos biográficos, literarios y bibliográficos de este conjunto de poetas. En lo que alude a Matos Fragoso, contábamos hasta el momento con los trabajos de Pannarale y, más recientemente, Martínez Carro y Ulla Lorenzo habían llamado la atención sobre su relevancia en el ámbito de la composición de comedias en colaboración al lado de autores como Cáncer o Belmonte. Faltaba, sin embargo, un trabajo de conjunto que combinase aspectos literarios y bibliográficos y reuniese todos aquellos fragmentos que conforman la obra de Matos Fragoso. Gracias a la investigación llevada a cabo por Vaiopoulos, ahora podemos conocer la actividad literaria de este poeta. 
2 La obra se divide en cuatro capítulos a los que siguen un apartado de conclusiones (p.135), otro en el que se recogen las siglas de las bibliotecas en las que se ha investigado (p. 139) y, finalmente, la bibliografía (p. 141) y la webgrafía (p. 159).

El primer capítulo (p. 11) tiene un carácter introductorio y en él se exponen de forma certera y sobre la base de un amplio de número de fuentes primarias y secundarias, conservadas en archivos y bibliotecas, los datos biográficos y bibliográficos conocidos sobre el poeta.

4 El capítulo segundo (p.15) se dedica íntegramente a su obra poética, que la autora estudia a efectos de datación, edición, así como en lo que se refiere al valor literario que adquirió en el campo cultural en el que se generó. Este estudio está seguido por un catálogo de la obra lírica de Matos, integrada por fichas de descripción bibliográfica que se ordenan de manera cronológica.

tercer capítulo (p.35) es el más breve del catálogo, puesto que el género narrativo fue también el menos trabajado por el autor portugués. Es interesante cómo Vaiopoulos ha recogido en este apartado no solo las dos relaciones que escribió, sino también los paratextos que compuso, cuatro dedicatorias y una aprobación. Quizás a este respecto se podría profundizar en la pista que este tipo de textos nos ofrecen en torno a las relaciones sociales del autor.

6 El teatro fue el género literario que ocupó, sin embargo, la mayor parte de su carrera literaria. Vaiopoulos dedica el magnífico capítulo cuarto (p. 39) a su estudio atento. Por una parte, logra con gran magisterio trazar el corpus del autor para después dedicarse a dibujar su actividad dramática en el contexto del ciclo calderoniano. A continuación, se sitúa el excepcional catálogo de las obras teatrales de Matos dividido en cuatro bloques que recogen las distintas facetas de su labor. En primer lugar, la autora atiende a las comedias publicadas en la parte de 1658, después a otras obras individuales; en tercer lugar, se ocupa de las comedias en colaboración, ámbito en el que Matos ocupó una importante posición; finalmente trata el teatro breve. De cada obra se recoge el inicio y final del texto, la tradición bibliográfica completa, en muchos casos integrada por impresos y manuscritos, acompañada de la localización de ejemplares; también la fortuna escénica de cada obra. Finalmente, se ofrece un apartado de revisión crítica y otro de observaciones. Cada una de las fichas constituye una publicación en sí misma. El trabajo que se observa detrás de cada una de ellas es ingente.

$7 \quad$ No hay duda de que la autoría de los textos dramáticos del Siglo de Oro es una de las dificultades de mayor envergadura a la que nos enfrentamos a la hora de estudiar y editar estas obras. En este sentido, puede considerarse cómo la estilometría está ayudando a resolver una parte de estos problemas. Vaiopoulos se hace eco de esta cuestión en la última parte del bloque dedicado a la obra teatral de Matos. En algunos casos los problemas de atribución vienen ocasionados, como era habitual en la época, por operaciones editoriales dudosas; en otras, sin embargo, la duda llegó al confundirse la letra del dramaturgo con la del copista Pseudo-Matos. También en este caso la autora ofrece fichas detalladas y minuciosas fichas de cada una de las obras cuya atribución autorial general dudas entre la crítica y aporta una primera sección bibliográfica, seguida de una dedicada a las representaciones de la obra y, finalmente, una destinada a la aportación que la crítica ha hecho con respecto a esta obra.

8 El magnífico catálogo razonado se cierra con un apartado de conclusiones en el que se destacan aquellas cuestiones de mayor relevancia del trabajo, tanto desde un punto de 
vista literario como bibliográfico. A continuación, se sitúa la estupenda nómina de bibliotecas consultadas. Se echa en falta la mención de la Hispanic Society o de la Biblioteca Nacional de Lisboa que, sin embargo, la autora sí ha consultado tal y como se indica en la página 18. Quizás podría ser interesante ampliar la búsqueda a otras bibliotecas extranjeras en las que también se conserva un fondo hispánico antiguo que puede ser de relevancia.

El trabajo se cierra con la bibliografía y la webgrafía manejadas; esta última ofrece una idea de la importancia que han adquirido los diferentes proyectos de investigación nacidos en la sociedad digital.

10 Son pocas las carencias que se pueden achacar a este trabajo excepcional. A este respeto, únicamente nos gustaría señalar que hemos echado en falta la inclusión de un índice final que permitiese volver sobre el título concreto o, incluso, sobre un verso inicial o final.

11 Más allá de esta cuestión, no cabe duda de que nos encontramos ante el fruto de una investigación excepcional y que resultaba muy necesaria en el ámbito de los estudios teatrales del Siglo de Oro. Los investigadores de este ámbito de estudios estamos, pues, de enhorabuena. Solo nos resta animar a su autora a que asuma ahora la significativa e indispensable labor de edición de la obra dramática de Matos Fragoso.

\section{AUTORES}

\section{ALEJANDRA ULLA LORENZO}

Universidad de Santiago de Compostela 